\title{
An educational tool to assist the design process of switched reluctance machines
}

\section{ABSTRACT}

The design of electric machines is a hot topic in the syllabuses of several undergraduate and graduate courses. With the development of hybrid and electrical vehicles, this subject is gaining more popularity, especially in electrical engineering courses. This paper presents a computeraided educational tool to guide engineering students in the design process of a switched reluctance machine (SRM). A step-by-step design procedure is detailed and a user guide interface (GUI) programmed in the Matlab® environment developed for this purpose is shown. This GUI has been proved a useful tool to help the students to validate the results obtained in their lecture assignments, while aiding to achieve a better understanding of the design process of electric machines. A validation of the educational tool is done by means of finite element method (FEM) simulations.

Keywords Computer-aided design, electrical engineering, sizing equations, switched reluctance motor.

\section{INDEX OF SYMBOLS}

$\begin{array}{ll}A & \text { Area }\left[\mathrm{mm}^{2}\right] \\ A_{s} & \text { Electric loading }[\mathrm{A} / \mathrm{m}] \\ B & \text { Flux density [T] } \\ b_{s y}, b_{r y} & \text { Width of stator/rotor yoke } \\ \beta_{s p}, \beta_{r p}, & \text { Stator/rotor polar angle }\end{array}$




$\begin{array}{ll}D & \text { Diameter [mm] } \\ F S & \text { Frame size } \\ \Phi & \text { Magnetic flux [Wb] } \\ \psi & \text { Flux linkage [Wb] } \\ g & \text { Air gap length [mm] } \\ h_{s p}, h_{r p}, h_{c} & \text { Height of stator/rotor pole or coil [mm] } \\ i & \text { Current [A] } \\ J & \left.\text { Current density [A/mm }{ }^{2}\right] \\ k_{e}, k_{d} & \text { Efficiency, duty cycle } \\ l & \text { Axial length [mm] } \\ L & \text { Inductance [H] } \\ n & \text { Speed [r/min] } \\ N_{s}, N_{r} & \text { Number of stator/rotor poles } \\ T & \text { Torque [N·m] } \\ P & \text { Power [W] } \\ q & \text { Number of phases } \\ R & \text { Reluctance } \\ T_{p h} & \text { Turns per phase } \\ V & \text { Voltage [V] } \\ \omega & \text { Angular speed [rad/s] } \\ \omega_{s p}, \omega_{r p}, \omega_{c} & \text { Width of stator/rotor pole or coil } \\ & \end{array}$

\section{INTRODUCTION}

Hybrid and electric vehicles have several advantages over ICE (internal combustion engine) powered vehicles such as higher efficiency or lower exhaust emissions [1]. Although several types of electric machines exist, SRMs offer appealing features including simple and rugged construction, brushless design, high temperature capability, or fault-tolerant operation among others [2,3]. They are even envisaged for electric vehicle (EV) in-wheel applications [4]. It is also known that SRMs have higher specific torque and efficiency than equivalent induction machines. SRMs have two main drawbacks, i.e. an important and an inherent difficulty in the control due to their inherent non-linear behavior since they operate under saturation conditions, and higher torque ripple than other electric machines. Consequently, SRMs are less applied in industrial environments and therefore much less studied in most electrical engineering courses than other types of electric machines [5]. However, SRMs are good candidates in applications which do not prioritize a very low torque ripple or a fine positioning, such as in electric vehicle 
drivetrains [1].

This work is aimed to foster students' interest and motivation in the design of electric machines topic. The learning system presented in this paper involves both machine sizing by means of an iterative system based on analytical equations and the design verification through a computeraided educational tool. This tool allows the students to validate the design method and calculations proposed in the lecture sessions. Computer-aided educational tools are appealing since they can improve the quality of education, especially in engineering courses. They can also be a good complement of lecture and practical sessions. It is also recognized that these tools can facilitate students learning, since they provide graphical interaction and flexibility, thus some difficult topics become more visual [6,7]. In addition some computer-aided tools allow testing and validating machines and drives in a virtual way, thus minimizing costs and difficulties of experimental tests.

The GUI presented in this paper provides a graphical, friendly and efficient environment that facilitates the design process of SRMs. The GUI allows introducing the main design parameters and restrictions of the SRM to be designed, such as the desired output power, rated speed, rated phase current, number of phases, configuration or materials among others, and calculates the dimensions and the main mechanical, electric and magnetic parameters which describe the behavior of the designed SRM.

It is worth noting that although there are several educational papers dealing with the topic of performance analysis and control of different types of electric machines $[5,7,8]$, the authors of this work have found no educational papers dealing with the topic of designing and sizing SRMs. 


\section{COURSE STRUCTURE AND DETAILS}

The computer assisted design of the SRM described in this paper is taught in the Plug-In Hybrid Electric Vehicles: Concept, design and project of Electric propulsion systems, a 10-weeks elective course of the eighth-semester Degree in Engineering taught at the ETSEIAT school of the Universitat Politècnica de Catalunya (UPC). This course has an estimated students' load of 3 ECTS (European Credit Transfer and Accumulation System). The lectures meet for two onehour lecture sessions every week, and every two weeks students attend a two-hour practical session in which the computer assisted motor design experiment is taught. The contents of the Plug-In Hybrid Electric Vehicles: Concept, design and project of Electric propulsion systems course are as follows:

- Hybrid electric vehicles

- Electric propulsions systems for vehicles

- Electric drive train design

- Design of a control drive system

- Analysis of integration of plug-in hybrid electric vehicles in the distribution grid

\section{THE SIZING PROCEDURE}

Electric machines are often initially designed and sized by applying the output equation, which relates the main machine parameters such as length, bore diameter, base speed, electric loading and magnetic flux density to the rated output power [9]. From this equation an estimation of the main dimensions can be obtained, which are the starting point in the design evaluation process. The sizing equation of the SRM can be written as,

$$
P_{\text {out }}=k_{e} \cdot k_{d} \cdot \frac{\pi^{2}}{120} \underbrace{\left(1-L_{u} / L_{a}\right)}_{k_{L}} \cdot\left(B \cdot A_{s}\right) \cdot D^{2} \cdot \cdot \cdot \cdot n_{S R M, r / \min }
$$


$k_{e}$ being the efficiency, $k_{d}$ the duty cycle, $L_{a}$ and $L_{u}$ being, respectively, the aligned and unaligned inductances, $B$ the stator pole flux density at the aligned position, $A_{s}$ the electric loading, $D$ the bore or stator inner diameter, $l$ the axial length of the motor and $n_{S R M}$ is the rated or base speed expressed in r/min. Note that (1) supposes constant peak values of phase currents and voltages.

However, to directly size the SRM from (1), some assumptions need to be established, such as the values of $k_{e}, k_{d}, k_{L}, B$ and $A_{s}$. The accuracy of the final solution will greatly depend on the degree of uncertainty of these assumptions. Therefore, a more accurate sizing procedure than the direct application of (1) is carried out in this work. Since the SRM is often used as a variablespeed actuator, both the rated output power and the base speed are usually design specifications. Therefore the output torque can be obtained from,

$$
T_{\text {out }}=\frac{P_{\text {out }}}{\omega_{S R M}}=\frac{30}{\pi} \frac{P_{\text {out }}}{n_{S R M, r / \min }}
$$

Fig. 1 summarizes the procedure applied to design the SRM, which is described in this section. 


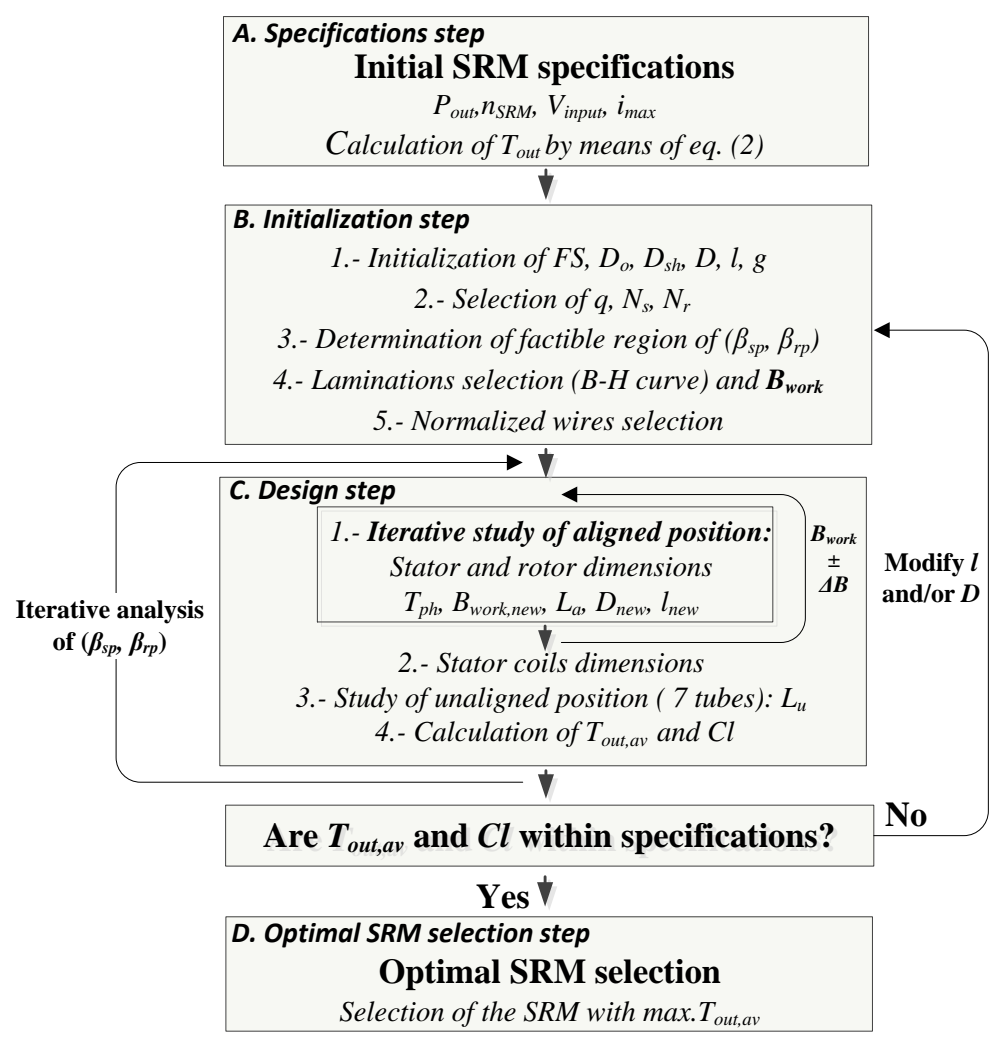

Fig. 1. Steps involved in the design procedure of the SRM.

\section{A. Specifications step}

To design a motor for a particular application, some initial specifications are required. SRM design specifications comprise the rated speed, rated output power, allowable flat constant peak value of the phase current, and the available supply voltage. Note that the output torque is fixed from the specified speed and power output, as indicated by (2).

\section{B. Initialization step}

In this phase, several initial values of important parameters of the SRM are selected, which are described below.

1. Initial values of the frame size, outer stator and shaft diameters and calculation of

the laminations length. The preliminary frame size $F S$ is selected according to Table 1 $[10,11]$. 
Table 1. Frame Size Selection for $1500 \mathrm{r} / \mathrm{min}$ Motors

\begin{tabular}{ccc}
\hline \hline $\begin{array}{c}\text { Rated speed } \\
\boldsymbol{\omega}(\mathbf{r} / \mathbf{m i n})\end{array}$ & $\begin{array}{c}\text { Output power } \\
\boldsymbol{P}_{\text {out }}(\mathbf{k W})\end{array}$ & $\begin{array}{c}\text { Frame size } \\
\text { FS }(\mathbf{m m})\end{array}$ \\
\hline 1500 & 0.12 & 63 \\
1500 & 0.18 & 63 \\
1500 & 0.25 & 71 \\
1500 & 0.37 & 71 \\
1500 & 0.55 & 80 \\
1500 & 0.75 & 80 \\
1500 & 1.10 & 90 \\
1500 & 1.50 & 90 \\
1500 & 2.20 & 100 \\
1500 & 3.00 & 100 \\
1500 & 4.00 & 112 \\
1500 & 5.50 & 132 \\
1500 & 7.50 & 132 \\
1500 & 11.0 & 160 \\
1500 & 15.0 & 160 \\
1500 & 18.5 & 180 \\
1500 & 22.0 & 180 \\
1500 & 30.0 & 200 \\
1500 & 37.0 & 225 \\
1500 & 45.0 & 225 \\
1500 & 55.0 & 250 \\
1500 & 75.0 & 280 \\
1500 & 90.0 & 280 \\
\hline \hline
\end{tabular}

Next, the stator outer diameter is calculated by applying,

$$
D_{o}=(F S-x) \cdot 2
$$

where $x$ is subtracted to account for the machine foot (in the example calculated in Section $\mathrm{V}$ it is assumed $x=3 \mathrm{~mm}$ ). The shaft diameter $D_{s h}$ is selected according to Table 2 [10].

Table 2. Normalized Frame Size and Shaft dimensions [IEC 60034]

\begin{tabular}{ccccccc}
\hline \multicolumn{2}{c}{ Frame size Frontal width Outer diameter } & \multicolumn{4}{c}{ Shaft dimensions (mm) } \\
$\boldsymbol{F S}(\mathbf{m m})$ & $\mathbf{A B}(\mathbf{m m})$ & $\boldsymbol{D}_{\boldsymbol{o}}(\mathbf{m m})$ & $\boldsymbol{D}_{\boldsymbol{s} \boldsymbol{h}}$ & $\boldsymbol{g}_{\boldsymbol{s} \boldsymbol{h}}$ & $\boldsymbol{f}_{\boldsymbol{s} \boldsymbol{h}}$ & $\boldsymbol{h}_{\boldsymbol{s} \boldsymbol{h}}$ \\
\hline 63 & 120 & 120 & 11 & 8.5 & 4 & 4 \\
71 & 136 & 136 & 14 & 11.0 & 5 & 5 \\
80 & 154 & 154 & 19 & 15.5 & 6 & 6 \\
90 & 170 & 174 & 24 & 20.0 & 8 & 7 \\
100 & 200 & 194 & 28 & 24.0 & 8 & 7 \\
112 & 230 & 218 & 28 & 24.0 & 8 & 7 \\
132 & 262 & 258 & 38 & 33.0 & 10 & 8 \\
160 & 310 & 314 & 42 & 37.0 & 12 & 8 \\
180 & 341 & 354 & 48 & 42.5 & 14 & 9 \\
200 & 380 & 394 & 55 & 49.0 & 16 & 10 \\
225 & 418 & 444 & 60 & 53.0 & 18 & 11 \\
250 & 473 & 494 & 65 & 58.0 & 18 & 11 \\
280 & 522 & 554 & 75 & 67.5 & 20 & 12 \\
315 & 622 & 624 & 80 & 71.0 & 22 & 14 \\
\hline
\end{tabular}


The bore diameter $D$ is initially set equal to the frame size, $D_{\text {ini }} \approx F S$, the axial length to $l_{\text {lini }} \approx$ $A B$ (see Fig. 2) with the restrictions $0.75 \cdot D_{i n i} \leq D \leq 1.25 \cdot D_{i n i}$ and $0.5 \cdot l_{i n i} \leq l \leq l_{\text {ini }}$. It is worth noting that these restrictions can be changed according to the specific SRM application.

The air gap length is also selected in this stage according to previous SRM design experience, which suggests $g$ values for small machines of $0.18-0.25 \mathrm{~mm}$ and for integral horsepower machines of $0.3-0.5 \mathrm{~mm}$. SRMs require small air gaps to achieve a high inductance ratio $L_{d} / L_{u}$, which allows maximizing power and torque densities. However, small air gaps tend to induce high surface loss due to the air gap flux harmonics, which can be significantly reduced by using high-quality rotor laminations.

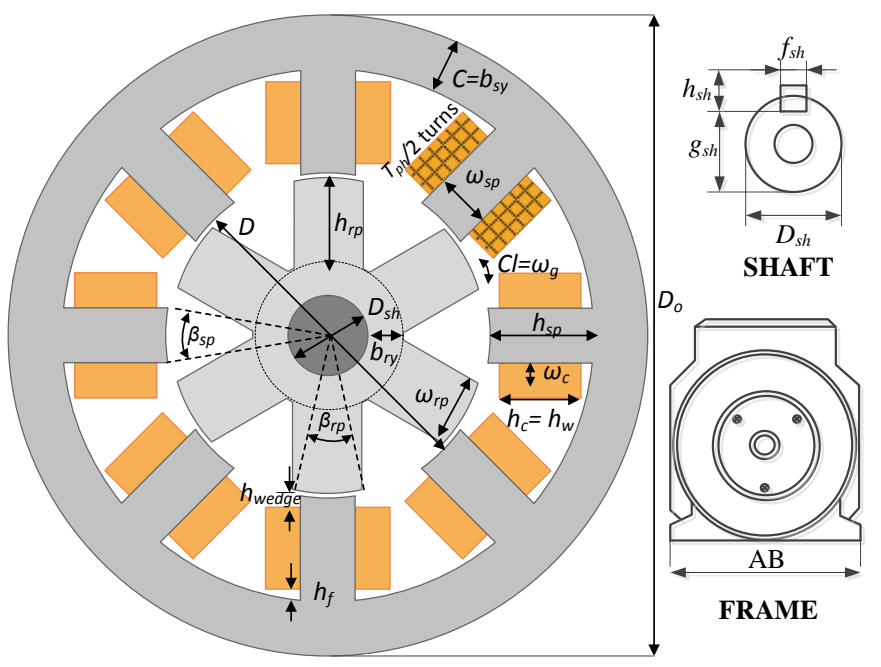

Fig. 2. Basic geometry of a 8/6 SRM.

2. Phases and poles number selection. The designer usually fixes both the number of stator and rotor poles, $N_{s}$ and $N_{r}$ respectively. Although there are many possible combinations, some of them are preferred, highlighting the $6 / 4(q=3$ phases $)$ and $8 / 6(q=4$ phases $)$ combinations. The 6/4 machine offers geometric simplicity and the use of a small number of power switches, whereas the $8 / 6$ structure exhibits lower torque ripple at the expense of requiring a converter with more switches and higher losses because of the higher switching frequency. 
3. Selection of the stator and rotor pole angles. In this paper a process to select the best pair of stator and rotor polar angles, $\beta_{s p}$ and $\beta_{r p}$ respectively, is applied since they greatly influence the final behavior of the SRM. The $\left(\beta_{s p}, \beta_{r p}\right)$ pair producing the greater torque is selected. To this end three conditions are imposed:

a. First condition. The stator pole angle $\beta_{s p}$ is usually set smaller than the rotor pole angle $\beta_{r p}$, i.e. $\beta_{s p}<\beta_{r p}$.

b. Second condition. The effective torque region is larger than the stroke angle $\varepsilon=360^{\circ} /\left(N_{r} \cdot q\right)$ but smaller than the stator pole angle $\beta_{s p}$. Note that $q=N_{s} / 2$ is the number of stator phases. Therefore, to ensure starting capability at any initial position, it must be accomplished $\beta_{s p}>\varepsilon$ . For a $8 / 6 \mathrm{SRM}$ it results in $\varepsilon=15^{\circ}$.

c. Third condition. The inductance profile of each stator phase repeats every $360^{\circ} / N_{r}$. Within the zone in which the stator and rotor pole arcs are not overlapped, the phase inductance remains at its minimum unaligned value $L_{u}$. To avoid any overlap between the stator and rotor poles in the unaligned position, the angle between the corners of two adjacent rotor poles must be greater than the stator pole arc. This condition is attained when $360^{\circ} / N_{r}-\beta_{r p}>\beta_{s p}$

The three conditions can be represented in a graph to describe a feasible triangle, as shown in Fig. 3. The feasible pairs of pole angles $\left(\beta_{s p}, \beta_{r p}\right)$ must lie within this triangle.

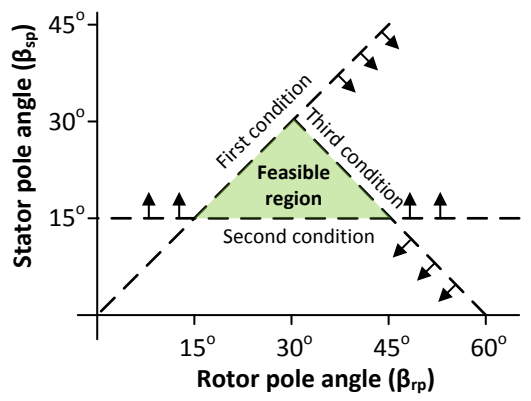

Fig. 3. Feasible triangle region for a $8 / 6 \mathrm{SRM}$. 
The feasible region restricts the possible combinations of stator and rotor pole angles but does not provide the better solution. It is possible to search for the combination $\left(\beta_{s p}, \beta_{r p}\right)$ that produces the maximum torque following the procedure described in section III.C [12], which is obtained from the full design of the SRM. Therefore, successive iterations must be performed to obtain the optimum value of the $\left(\beta_{s p}, \beta_{r p}\right)$ pole angles.

4. Laminations material selection. The stator and rotor laminations material and thickness must be selected. During the design phase it is assumed that the stator pole operates at the point $B_{\text {work }}$ of the $B-H$ magnetization curve, as shown in Fig. 4. This point is used to limit the maximum flux density in any part of the SRM. It is known that the points with maximum magnetic flux density are located in the stator poles, so the stator poles are designed to operate at a magnetic flux density $B_{\text {work }}$ below the saturation point. From this value, the rest of the machine can be designed.

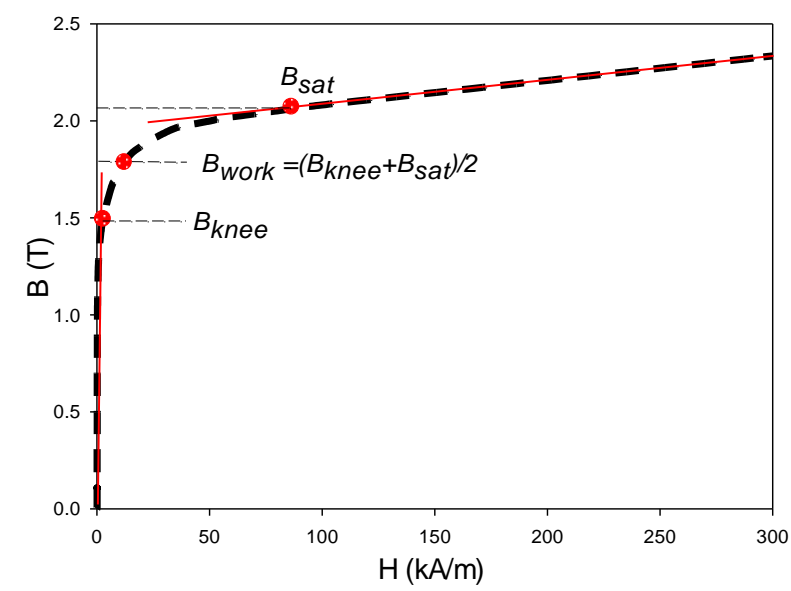

Fig. 4. B-H curve example for M235-35A steel laminations

5. Normalized wires selection. The cross-section of the conductors is calculated from the number of phases $q$, the peak phase current $i_{\max }$ (which has been initially settled) and the current density $J$ (typical values for air cooled motors are within 4-8 $\mathrm{A} / \mathrm{mm}^{2}$ ) as [9]: 


$$
A_{\text {conductor }}\left(m m^{2}\right)=\frac{i_{\max }}{J\left(A / m m^{2}\right) \cdot \sqrt{q}}
$$

The section of the normalized conductors is obtained by selecting from Table 3 the section closer but greater than the value obtained from (4).

TABLE 3. Normalized conductors Dimensions (American Wire Gauge)

\begin{tabular}{cccc}
\hline \hline AWG & $\boldsymbol{D}_{\boldsymbol{w}}(\mathbf{m m})$ & $\boldsymbol{A}_{\boldsymbol{c}}\left(\mathbf{m m}^{\mathbf{2}}\right)$ & $\mathbf{R}_{\mathbf{s}}(\mathbf{O h m s} \mathbf{k m})$ \\
\hline 1 & 7.348 & 42.400 & 0.407 \\
2 & 6.544 & 33.600 & 0.513 \\
3 & 5.827 & 26.700 & 0.647 \\
4 & 5.189 & 21.200 & 0.815 \\
5 & 4.621 & 16.800 & 1.028 \\
6 & 4.115 & 13.300 & 1.296 \\
7 & 3.665 & 10.500 & 1.634 \\
8 & 3.264 & 8.370 & 2.061 \\
9 & 2.906 & 6.630 & 2.599 \\
10 & 2.588 & 5.260 & 3.277 \\
11 & 2.305 & 4.170 & 4.132 \\
12 & 2.503 & 3.310 & 5.211 \\
13 & 1.828 & 2.620 & 6.571 \\
14 & 1.628 & 2.080 & 8.286 \\
15 & 1.450 & 1.650 & 10.450 \\
16 & 1.291 & 1.310 & 13.170 \\
17 & 1.150 & 1.040 & 16.610 \\
18 & 1.024 & 0.823 & 20.950 \\
19 & 0.912 & 0.653 & 26.420 \\
20 & 0.812 & 0.518 & 33.310 \\
21 & 0.723 & 0.410 & 42.000 \\
22 & 0.644 & 0.326 & 52.960 \\
23 & 0.573 & 0.258 & 66.790 \\
24 & 0.511 & 0.205 & 84.220 \\
25 & 0.455 & 0.162 & 106.200 \\
26 & 0.405 & 0.129 & 133.900 \\
27 & 0.361 & 0.102 & 168.900 \\
28 & 0.321 & 0.081 & 212.900 \\
29 & 0.286 & 0.064 & 268.500 \\
30 & 0.255 & 0.051 & 338.600 \\
\hline & & &
\end{tabular}

\section{Design step}

In this stage, an iterative process is performed to determine the main SRM dimensions. It is based on the analysis of the aligned and unaligned positions since (1) states that SRMs' performance is greatly influenced by $k_{\mathrm{L}}$ (at the rated phase current $k_{\mathrm{L}}$ usually falls within the 
range $\left.0.65<k_{L}<0.75\right)$ which depends on the ratio between the aligned and unaligned inductances. Therefore, the sizing process of the SRM requires an accurate calculation of both inductances. To this end, in this section the values of both $L_{u}$ and $L_{a}$ inductances are calculated by means of reluctance models, although it is known that this method provides an inherent error, especially due to the calculation of the unaligned inductance [9].

1. Iterative study of the aligned position. The aligned position is reached when the symmetry axes of the stator and rotor poles coincide. The analytical calculation of the flux linkages for the aligned position neglects the leakage flux. Initially, a prospective flux density $B_{\text {work }}$ in the stator poles is assumed. From it, the flux densities of different sections of the SRM are calculated by applying flux continuity conditions, assuming that the areas of the cross sections (air gap, stator and rotor poles and yokes) are known.

Now the stator dimensions can be calculated on the basis of maximum magnetic flux density in the stator. A good practice consists in limiting the flux density of the stator yoke around half the value in the stator poles, that is, $B_{s, y}=0.5 \cdot B_{\text {work }}$ [9]. The width $\omega_{s p}$ of the stator poles is selected to accommodate the pole flux density, so

$$
\omega_{s p}=D \cdot \beta_{s p} / 2
$$

Since the flux density in the stator core is limited to one-half of the flux density in the stator poles, the stator yoke width results in,

$$
b_{s y} \approx \omega_{s p}
$$

Next, the height of the stator poles is calculated from Fig. 2 as,

$$
h_{s p}=\frac{D_{0}-2 \cdot b_{s y}-D}{2}
$$

Now, the rotor dimensions are selected. In [9] it is suggested to limit the flux density of the rotor yoke around $80 \%$ of that in the stator poles, thus $B_{r y}=0.8 \cdot B_{\max }$. Based on the flux 
density condition above, the rotor yoke width results in,

$$
b_{r y}=\omega_{s p} / 1.6
$$

Finally, from the geometry shown in Fig. 1, the rotor pole height is calculated as,

$$
h_{r p}=\frac{D-2 \cdot g-D_{s h}-2 \cdot b_{r y}}{2}
$$

Once the stator and rotor dimensions are known, the flux densities in the different parts of the SRM can be calculated, so the relative magnetic permeability $\mu_{r}$ in each section of the SRM is obtained from the $B-H$ curve of the steel laminations. Next, from the flux path lengths and the magnetic field densities in the different parts of the SRMs, the magnetomotive forces (MMFs) are obtained by applying the equivalent magnetic circuit corresponding to the aligned position, which is shown in Fig. 5.

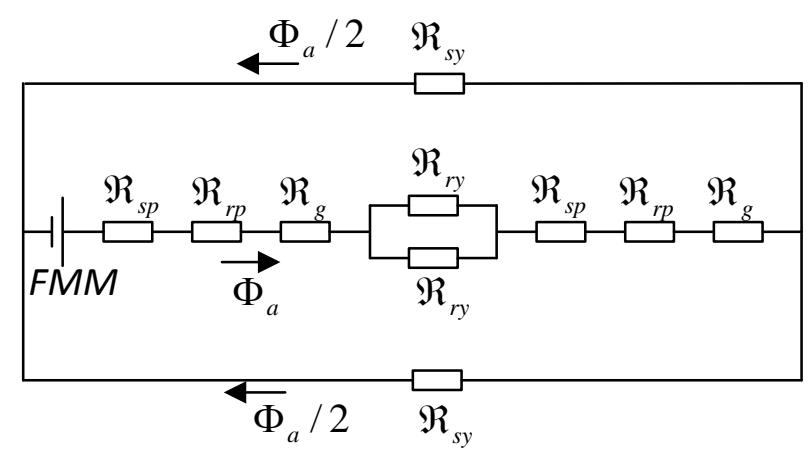

Fig. 5. Aligned position equivalent magnetic circuit for the 8/6 SRM.

The equivalent reluctance of the equivalent magnetic circuit corresponding to the aligned position shown in Fig. 5 is,

$$
\mathfrak{R}_{t o t, a}=2 \cdot\left(\mathfrak{R}_{s p}+\mathfrak{R}_{r p}+\mathfrak{R}_{g}\right)+\left(\mathfrak{R}_{s y}+\mathfrak{R}_{r y}\right) / 2
$$

The reluctances are calculated by applying $\Re=l /\left(\mu_{o} \cdot \mu_{r} \cdot A\right)$, so the length of the magnetic paths, the cross sectional areas and the relative permittivites of each path must be known, which are listed in Table 4. 
Table 4. Magnetic Path Lengths, Cross Sections And Flux Densities

\begin{tabular}{cccc}
\hline \hline Part & Length & Cross section & Flux density \\
\hline Stator pole & $l_{s p}=h_{s p}+b_{s y} / 2$ & $A_{s p}=\beta_{s p} \cdot(D / 2) \cdot l \cdot f_{s}$ & $B_{s p}=B_{w o r k}$ \\
Stator yoke & $l_{s y}=\pi \cdot\left(D_{o}-b_{s y}\right) / 2$ & $A_{s y}=b_{s y} \cdot l \cdot f_{s}$ & $B_{s y}=B_{s p} / 2$ \\
Rotor pole & $l_{r p}=h_{r p}\left(D / 2-D_{s h} / 2-h_{r p}-g\right) / 2$ & $A_{r p}=\beta_{r p} \cdot(D / 2) \cdot l \cdot f_{s}$ & $B_{r p}=B_{s p} \cdot A_{s p} / A_{r p}$ \\
Rotor yoke & $l_{r y}=\pi \cdot\left(D / 2-h_{r p}-g+D_{s h} / 2\right) / 2$ & $A_{r y}=\left(D / 2-h_{r p}-g\right) \cdot l \cdot f_{s}$ & $B_{r y}=0.8 \cdot B_{s p}$ \\
Gap & $l_{g}=g$ & $A_{g}=\left(A_{s p}+A_{r p}\right) / 2 f_{s}$ & $B_{g}=B_{s p} \cdot A_{s p} / A_{g}$ \\
\hline
\end{tabular}

$f_{s}$ is the laminations stacking factor

Neglecting the leakage paths, the magnetic flux flowing from stator to rotor when considering the aligned position is obtained as,

$$
\Phi_{a}=B_{s p} \cdot A_{s p}
$$

And the total magnetomotive force is obtained as,

$$
F M M=\Phi_{a} \cdot \Re_{t o t, a}=B_{s p} \cdot A_{s p} \cdot \Re_{t o t, a}
$$

From (12) the number of turns per phase is obtained, which must be an even number,

$$
T_{p h}=\text { int }_{\text {even }}\left(F M M / i_{\text {max }}\right)
$$

Next, the magnetomotive force is recalculated from the number of turns as,

$$
F M M^{*}=T_{p h} \cdot i_{\max }
$$

Finally, the FMM obtained from (14) is compared with the one calculated from (12) and if the error is greater than a certain tolerance value $\varepsilon$, an iteration process is applied to adjust the initial prospective value of the flux density $B_{\text {work }}$ until the error is below the tolerance value,

$$
\begin{aligned}
& \text { If } F M M^{*}<F M M-\varepsilon \text { then } B_{\text {work,new }}=B_{\text {work }}+0.1(\mathrm{~T}) \\
& \text { If } F M M^{*}>F M M+\varepsilon \text { then } B_{\text {work,new }}=B_{\text {work }}-0.1(\mathrm{~T})
\end{aligned}
$$

Finally, the aligned inductance is calculated as,

$$
L_{a}=T_{p h} \cdot \Phi_{a} / i_{\max }
$$


2. Stator coils dimensions. The stator coil area is the product of the coil width $\omega_{c}$ by the coil height $h_{c}$ and by a coil fill factor $K_{u}$, which can also be expressed as the product of the conductors cross section area $a_{c}$ by half of the number of turns $T_{p h}$ per phase,

$$
K_{u} \cdot h_{c} \cdot \omega_{c}=a_{c} \cdot \frac{T_{p h}}{2}
$$

The maximum value of $\omega_{c}$ is obtained from the geometry in Fig. 2 as,

$$
\omega_{c}=\frac{1}{2} \cdot\left[\frac{\pi \cdot D}{N_{s}}-\left(\beta_{s} \cdot \frac{D}{2}+C l\right)\right]
$$

$\mathrm{Cl}$ being the clearance between consecutive coils.

From (17) and (18) it results,

$$
h_{c}=\frac{a_{c} \cdot T_{p h}}{K_{u}}\left[\frac{\pi \cdot D}{N_{s}}-\left(\beta_{s} \cdot \frac{D}{2}+C l\right)\right]^{-1}
$$

Next, since the coil must be placed between two consecutive stator poles and some extra space is required to ensemble the coils, the stator pole height $h_{s p}$ is obtained from the coil height $h_{c}$ by applying a security factor,

$$
h_{s p}=1.2 \cdot h_{c}
$$

\section{Study of the fully unaligned position. Calculation of $\boldsymbol{L}_{u}$.}

From (1) and (2) it is clear that to obtain the output power and torque power of the machine, both the aligned and fully unaligned inductances are required. In the unaligned position the center of the interpolar rotor gap coincides with the midpoint of the stator pole. In this case the leakage flux cannot be omitted, so the leakage paths must be calculated analytically. For this purpose seven flux paths are analyzed [9] to calculate the unaligned inductance (see Fig. 6). For the $i$-th flux path the length $l_{\text {element }, i}$, cross section $A_{\text {element, } i}$, magnetic field density $B_{\text {element, }, \text {, magnetic flux }} \Phi_{\text {element,I }}$ and reluctance $\mathfrak{R}_{\text {element }, i}$ of each element, as well as the total 
$M M F_{i}$ across each path must be calculated by applying $M M F_{i}=\sum_{\text {elements }} \Phi_{\text {element }, i} \Re_{\text {element }, i}$. Then, the unaligned inductance contribution due to the $i$-th path is calculated as $L_{u, i}=T_{p h} \cdot \Phi_{\text {element,i }} i i_{\max }$. Finally, the total unaligned inductance is calculated as the sum of all contributions,

$$
L_{u}=\sum_{i=1 \ldots 7} L_{u, i}
$$

Further details of the calculation process are found in $[9,13]$.

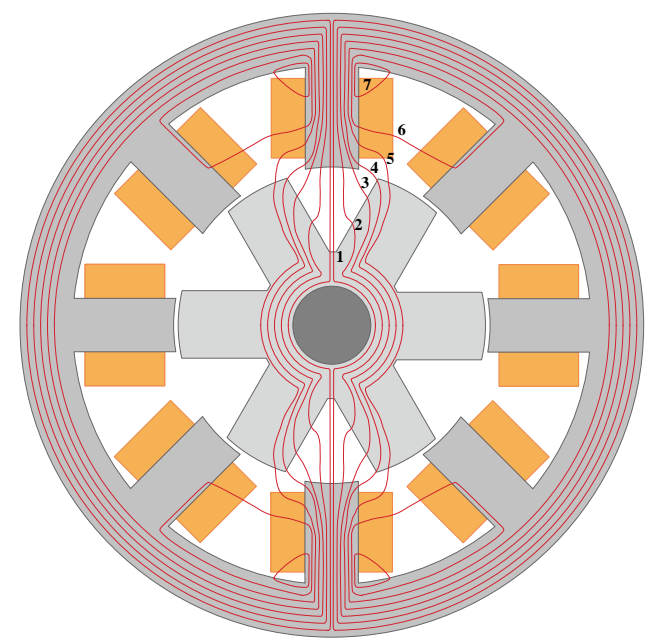

Fig. 6. Flux paths considered to calculate the unaligned inductance.

4. Calculation of the output torque and the coils clearance. By assuming that during a stroke the current remains almost constant, the SRM torque can be calculated from the electromechanical energy conversion as [14],

$$
T_{\text {out }}=\frac{\partial W_{\text {mec }}}{\partial \theta} \approx\left[\frac{\partial W}{\partial \theta}\right]_{i=c o n s t}
$$

Where $\theta$ is the angular displacement and $W$ is calculated from the magnetization curves as indicated in Fig. 7. Therefore, the flux linkages against the current characteristic must be calculated for both the aligned and unaligned positions, assuming that the current is almost constant between the unaligned and aligned positions. The torque per stroke of the SRM is obtained from the area between the aligned and unaligned positions, which may be calculated 
by applying the trapezoidal integration rule. This calculation discretizes the current into $n$ points $\left(\Delta i=i_{\max } / n\right)$ and calculates the corresponding flux linkages for both the aligned and unaligned positions.

The mechanical work per stroke done is obtained by calculating the area enclosed between the aligned and unaligned flux linkage versus current curves depicted in Fig. 7 as $[9,13]$, $W=W_{a}-W_{u}=\left[\left(\Psi_{1}+\Psi_{2}+\ldots+\Psi_{n-1}\right) \cdot \Delta i+\Psi_{n} \cdot \Delta i / 2\right]-\Psi_{u} \cdot i_{\max } / 2(23)$

Since the number of strokes or current pulses in a complete revolution is $S=N_{s} \cdot N_{r} / 2$, the average torque is obtained by applying,

$$
T_{\text {out }, a v}=\frac{S \cdot W \cdot}{2 \cdot \pi}=\frac{N_{s} \cdot N_{r} \cdot W}{4 \cdot \pi}
$$

If $T_{\text {out av }}$ doesn't match with the initial specifications, i.e. $0.95 \cdot T_{\text {out }} \leq T_{\text {out av }} \leq 1.05 \cdot T_{\text {out }}$ it is necessary to modify the stack length accordingly and to recalculate the SRM (see Fig. 1).

The clearance between adjacent coils is also calculated in this step. If the resulting clearance $C l$ is lower than a minimum specified value, the bore diameter $D$ must be modified to allow space enough for assembling and disassembling the coils in the stator, so the SRM must be recalculated (see Fig. 1).

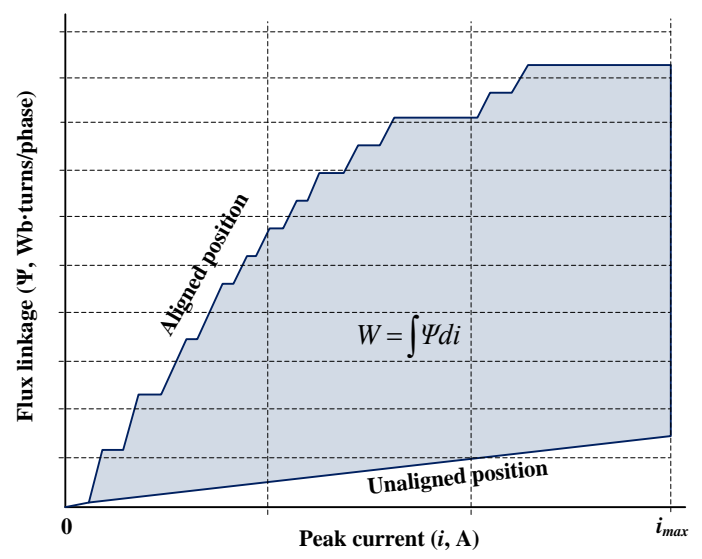

Fig. 7. Aligned and unaligned magnetization curves of the SRM, from which the average torque is calculated. 


\section{Optimal SRM selection step}

The selection of the optimal SRM is based on the solution achieving maximum torque. For all combinations $\left(\beta_{s p}, \beta_{r p}\right)$ explored during the design phase, the one achieving the maximum average torque is selected.

\section{The Matlab GUI DeVeloped}

This section describes the Matlab® graphical user interface (GUI) developed to assist the students in designing the SRM and validating the results attained in the assignments of the lecture sessions. The main window of the GUI consists of three main blocks, as illustrated in Fig. 8.

The first block consists of a set of buttons allowing the user to run a new SRM calculation, plot a drawing of the SRM or start a new design. In the second block the user sets the initial design specifications, including $P_{\text {out }}, n_{S R M}, N_{s} / N_{r}, g$, laminations material, $B_{\text {work, ini }}, i_{\text {max }}, J_{\text {max }}$ and the geometric restrictions of the coils. The third block displays the output values provided by the program, which include the final dimensions of the SRM and diverse performance parameters as well as a graphical window which allows the user selecting among the B-H curve, the magnetization curves of the designed SRM, and the set of $\left(\beta_{s p}, \beta_{r p}\right)$ solutions explored during the iterative design process. 


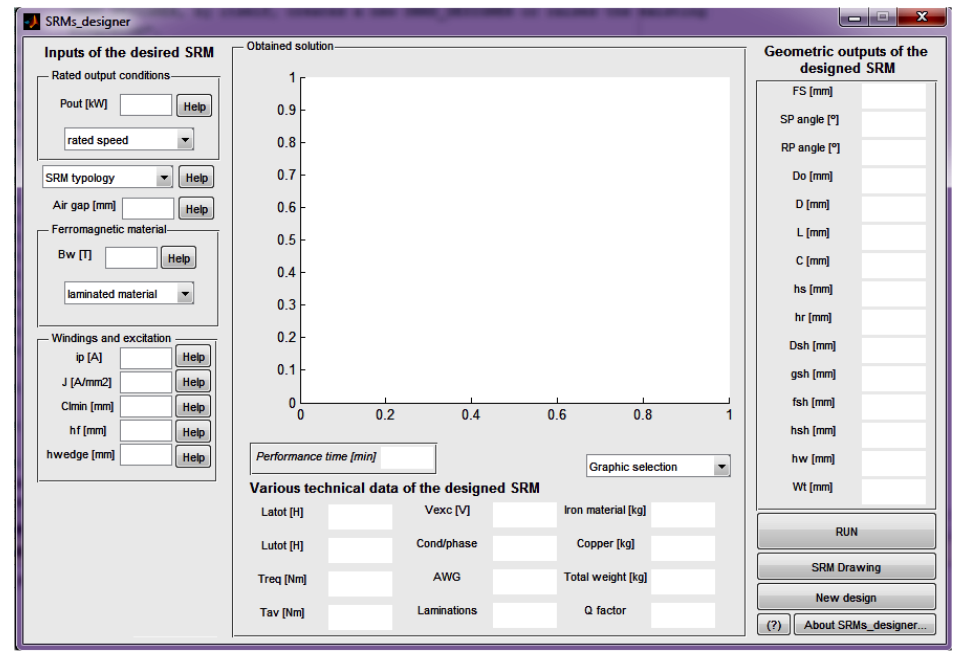

Fig. 8. General aspect of the main window of the SRM Designer GUI application.

Fig. 9 displays the three main sections of the GUI.

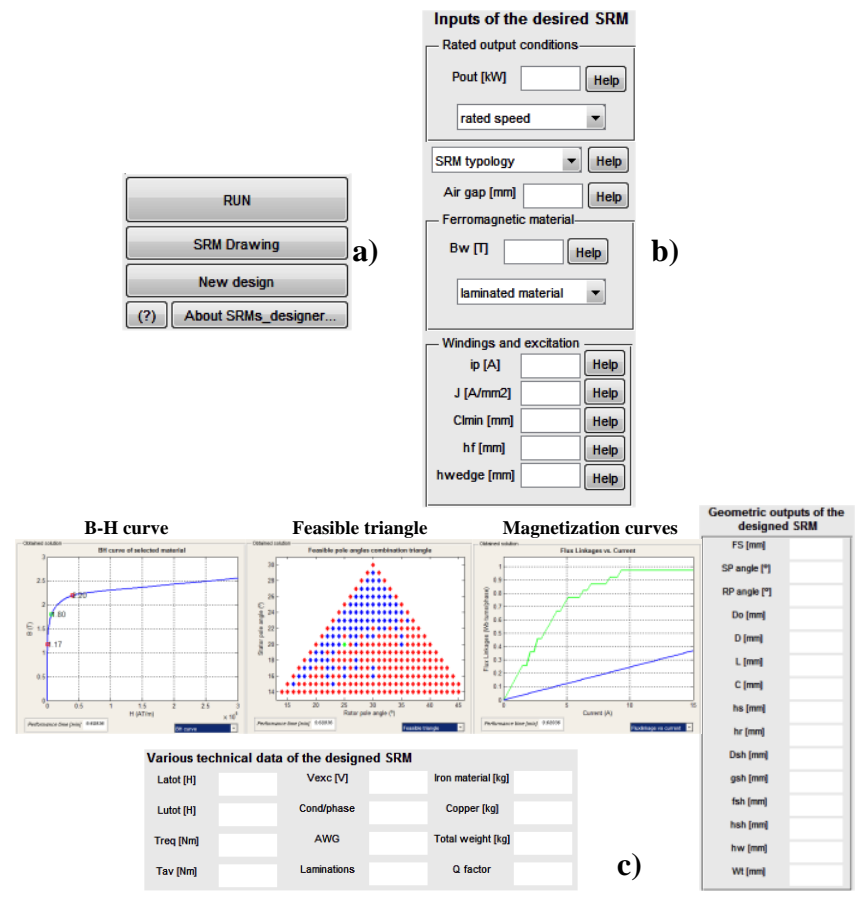

Fig. 9. a) Run, drawing and other buttons b) Initial specifications block of the GUI. c) Outputs section and graphical information provided by the GUI.

\section{Results AND FEM VALIDATION}

In this section a SRM is designed from the design specifications established by the user such as 
the rated speed, flat value of current and output power among others. The results for a given SRM attained by the GUI, which is based on the analytical design method described in Section III are presented and afterwards validated through FEM simulations.

Table 5 shows the main design parameters sought of the SRM. These parameters are introduced in the inputs block of the GUI in order to size the SRM.

Table 5. Main SRM specifications

\begin{tabular}{lc}
\hline \multicolumn{1}{c}{ Quantity } & Value \\
\hline Output power, $P_{\text {out }}$ & $5000 \mathrm{~W}$ \\
Rated speed, $n_{S R M}$ & $1500 \mathrm{r} / \mathrm{min}$ \\
Topology & $8 / 6$ \\
Number of phases, $q$ & 4 \\
Stator poles flux density, $B_{\text {work }}$ & $1.8 \mathrm{~T}$ \\
Current, flat value, $i_{\text {max }}$ & $15 \mathrm{~A}$ \\
Air gap length, $g$ & $0.4 \mathrm{~mm}$ \\
Steel laminations & $\mathrm{M} 235-35 \mathrm{~A}$ \\
\hline
\end{tabular}

Table 6 summarizes some of the parameters outputted by the GUI.

Table 6. Geometry of the optimized SRM

\begin{tabular}{lc}
\hline \hline \multicolumn{1}{c}{ Quantity } & Value obtained \\
\hline Stator polar angle, $\beta_{s}$ & $25^{\circ}$ \\
Rotor polar angle, $\beta_{r}$ & $20^{\circ}$ \\
Frame size, $F S$ & 112 \\
Outer diameter, $D_{0}$ & $218 \mathrm{~mm}$ \\
Bore diameter, $D$ & $109.6 \mathrm{~mm}$ \\
Shaft diameter, $D_{s h}$ & $28.0 \mathrm{~mm}$ \\
Stack length, $l$ & $132.3 \mathrm{~mm}$ \\
Stator pole height, $h_{s p}$ & $35.9 \mathrm{~mm}$ \\
Rotor pole height, $h_{r p}$ & $29.0 \mathrm{~mm}$ \\
Stator yoke width, $C=b_{s y}$ & $18.3 \mathrm{~mm}$ \\
Rotor yoke width, $b_{r y}$ & $11.4 \mathrm{~mm}$ \\
Air gap length, $g$ & $0.4 \mathrm{~mm}$ \\
Number of turns per phase, $T_{p h}$ & $212 / 2$ \\
\hline
\end{tabular}

Next, a validation of the SRM design procedure detailed in Section III is performed by means of FEM simulations, which is a widely used method for electromagnetic design and validation. The FEMM 4.2 package software was used [15] for this purpose. Figs. 10 show the mesh and the 
magnetic flux density distribution for the aligned and fully unaligned positions obtained by applying the FEM model of the SRM dealt with. The mesh is composed of 8168 triangular elements and a total of 4126 nodes.
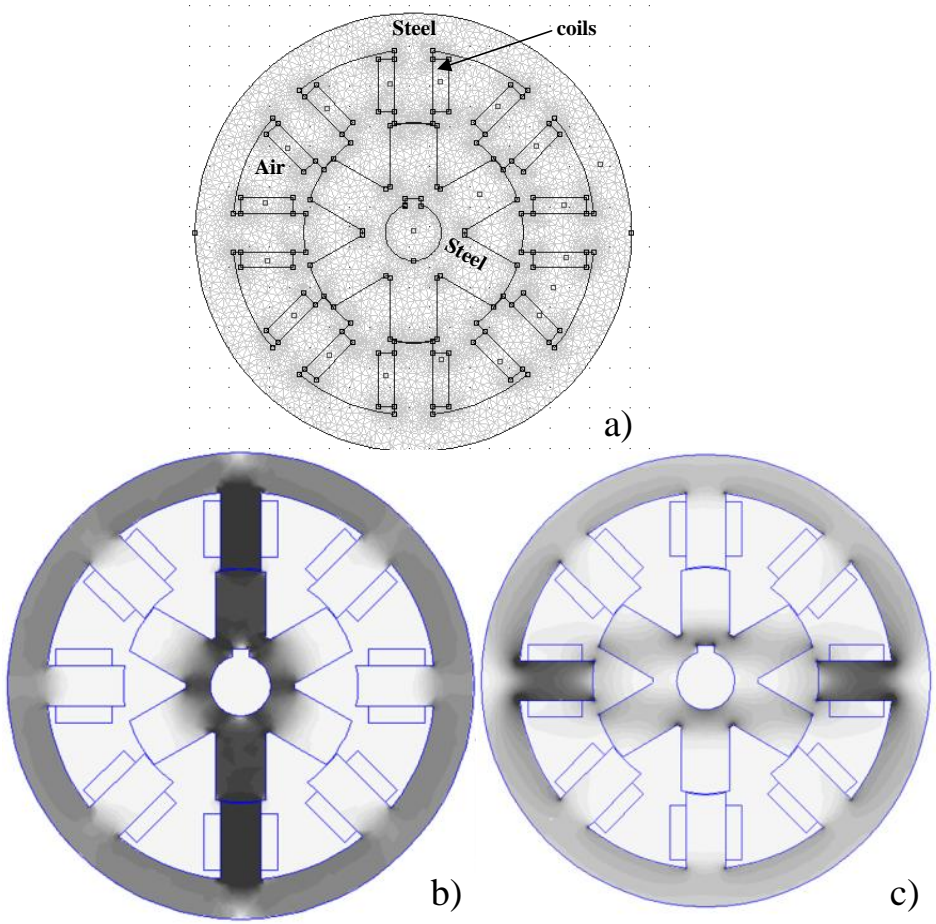

Fig. 10. a) Mesh of the analyzed SRM. FEM results of the flux density distribution. a) Aligned position flux density. b) Completely unaligned position flux density.

Table 7 compares the results obtained by means of both the Matlab® GUI and FEMM software. According to these results, the solution calculated through the analytical process presented in this paper agrees reasonably well with the results provided by the FEM model, thus being a validation of this design procedure.

Table 7. Results Summary

\begin{tabular}{lccc}
\hline \hline \multicolumn{1}{c}{ Quantity } & Design algorithm & FEM & Error \\
\hline Stator pole average flux density, $B_{w}$ & $1.8 \mathrm{~T}$ & $2.0 \mathrm{~T}$ & $11.1 \%$ \\
Aligned inductance, $L_{a}$ & $68.2 \mathrm{mH}$ & $70.5 \mathrm{mH}$ & $3.4 \%$ \\
Aligned inductance, $L_{u}$ & $24.6 \mathrm{mH}$ & $19.8 \mathrm{mH}$ & $19.5 \%$ \\
Flux linkage aligned position, $\psi_{a}$ & $0.99 \mathrm{~Wb}$ & $1.06 \mathrm{~Wb}$ & $7.1 \%$ \\
Flux linkage unaligned position, $\psi_{u}$ & $0.37 \mathrm{~Wb}$ & $0.30 \mathrm{~Wb}$ & $3.3 \%$ \\
\hline
\end{tabular}




\section{Assessment Of The Educational ToOL}

This educational tool was developed at the Electrical Engineering Department of the UPC. It was intended to provide students a fast and visual system to validate the design of SRMs with the aim of stimulating the students' interest in the design of electrical machines. It was taught to 46 students of the Plug-In Hybrid Electric Vehicles. Concept, design and project of Electric propulsion systems course in the second semester of the 2013-2014 academic year. To assess the impact of the computer-aided educational tool in their learning performance, the students were asked to fill a questionnaire. Students had to grade the six-question form according to the fivelevel Likert item, where 1 means strongly disagree and 5 means strongly agree. The six questions and the students' responses are reported in Table 8.

Table 8. Students' responses to the questionnaire.

\begin{tabular}{|c|c|c|c|c|c|c|}
\hline Question & 1 & 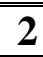 & $\overline{3}$ & 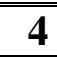 & 5 & Average \\
\hline $\begin{array}{l}\text { The computer aided session is well related to the topics that I am } \\
\text { studying in the lectures }\end{array}$ & 0 & 1 & 7 & 22 & 16 & 4.15 \\
\hline $\begin{array}{l}\text { The computer aided session has helped me to understand the } \\
\text { course topics }\end{array}$ & 0 & 0 & 6 & 25 & 15 & 4.20 \\
\hline The SRM design GUI is user friendly and intuitive & 0 & 0 & 4 & 24 & 18 & 4.30 \\
\hline $\begin{array}{l}\text { I would recommend this simulation experiment to be used in } \\
\text { forthcoming editions of the course }\end{array}$ & 0 & 0 & 5 & 22 & 19 & 4.30 \\
\hline $\begin{array}{l}\text { I would like to go beyond the computer experiment and do } \\
\text { research on my own }\end{array}$ & 0 & 0 & 9 & 23 & 14 & 4.11 \\
\hline $\begin{array}{l}\text { This methodology lets provide me with skills I expect to use in } \\
\text { future }\end{array}$ & 0 & 1 & 8 & 23 & 14 & 4.09 \\
\hline
\end{tabular}

Global average

4.19

As shown in Table 8 , the average grade was 4.15 in the $1-5$ scale. Therefore it can be concluded that this two-hour computer-aided session helps students in consolidating their pervious knowledge while stimulating their interest in the design of electric machines. 


\section{CONCLUSION}

This paper has presented a computer-aided educational tool to assist the design process of a SRM. The main objective of this tool is to help electrical engineering students during the design process of a SRM, therefore fostering students' motivation in the area of design of electrical machines. The paper has covered the technical aspects of the design steps, a sizing example of a SRM by using the educational tool presented here, and the results validation by means of FEM simulations. Finally, an assessment of the students' satisfaction about the usefulness and impact on learning performance related to the use of this tool has been presented. The preliminary results of the assessment summarized in Section VI related to students' satisfaction with the educational aspects of the educational tool suggest that it is a helpful tool for improving students' motivation and learning effectiveness in the design of electric machines.

\section{REFERENCES}

[1] B. Bilgin, A. Emadi, M. Krishnamurthy, 'Design considerations for switched reluctance machines with a higher number of rotor poles', IEEE Trans. Ind. Electron., 59/10 (2012) 3745-3756.

[2] S. M. Lukic, A. Emadi, 'State-switching control technique for switched reluctance motor drives: theory and implementation’, IEEE Trans. Ind. Electron., 57/9 (2010), 2932-2938.

[3] V.P. Vujicić, 'Minimization of torque ripple and copper losses in switched reluctance drive', IEEE Trans. Power Electron. 27/1 (2012), 388-399.

[4] S. P. Nikam, V. Rallabandi, B. G. Fernandes, A High-torque-density permanent-magnet free motor for in-wheel electric vehicle application', IEEE Trans. Ind. Appl., 48/6 (2012), 22872295.

[5] J.-R. Riba, A. Garcia, and L. Romeral, 'A computer experiment to simulate the dynamic behavior of electric vehicles driven by switched reluctance motors', Int. Jour. Elect. Eng. Edu., 51/4 (2014), 368-382.

[6] C. Gencer, M. Gedikpinar, 'A computer-aided educational tool for induction motors', Comp. Appl. Eng. Edu., 20/3 (2012), pp. 503-509. 
[7] H. Isfahani, S. Vaez-Zadeh, S. Hasanzadeh, 'An educational toolbox for performance analysis of line-start permanent magnet synchronous motors', Comp. Appl. Eng. Edu., 22/3 (2014), 452-462.

[8] R. J. Romero-Troncoso, A. Garcia-Perez, E. Cabal-Yepez, R. A. Osornio-Rios, 'Experimental system for teaching induction motor faults during the startup transient and steady state', Comp. Appl. Eng. Edu., 22/1 (2014), 33-38.

[9] R. Krishnan, Switched reluctance motor drives. Modeling, simulation, analysis, design and applications, Ed. 2001, CRC Press, Boca Raton, Florida, 2001.

[10]IEC 60072-1. Dimensions and output series for rotating electrical machines - Part 1: Frame numbers 56 to 400 and flange numbers 55 to 1080. Publication date: 1991-02-01

[11]ABB. [online] URL: <http://www.abb.es/product/es/> [Consult: 20/11/2014].

[12]R. Arumugam, J. F. Lindsay, R. Krishnan, 'Sensitivity of pole arc/pole pitch ratio on switched reluctance motor performance', in Proc. IEEE IAS Ann. Mtg., Vol. 1, pp. 50-54, Pittsburgh, Oct. 1988.

[13]P. Vijayraghavan, 'Design of switched reluctance motors and development of a universal controller for switched reluctance and permanent magnet brushless dc motor drives', PhD Dissertation, Blacksburg, Virginia, Nov. 15, 2001.

[14]T. J. E. Miller, Electronic Control of Switched Reluctance Machines, Newnes, Ed. 2001, Jordan Hill, Oxford, 2001.

[15]D. C. Meeker, Finite Element Method Magnetics, Version 4.2 (25Aug2013 Build), http://www.femm.info. 